\title{
Mycoplasma hominis: More than just An Innocent Bystander \\ Nulens $E^{*}$ and Reynders $M$
}

Laboratory Medicine, Department of Medical Microbiology, AZ Sint -Jan Bruges - Ostend, Bruges, Belgium

\section{Commentary}

Recently, a patient with an immunodeficiency was admitted in our hospital with fever, pain and a large abscess in the pelvic region, after an incomplete treatment of prostatitis with ciprofloxacin, for which no causal agent was not sought. For several weeks, he was treated with different beta-lactam antibiotics and vancomycin, however only a partial clinical response was achieved. On the other hand, the development of de novo abscess formation in the lumbar region, and the development of cutaneous ulcers and abscesses were seen. Finally, after several weeks of treatment, in a cutaneous biopsy Mycoplasma hominis was identified with the 16S rRNA gene sequencing [1].

M. hominis belongs to the commensal flora of the genitourinary tract, and the presence is associated with a low socio-economic status, hormonal changes, ethnicity and the number of sexual partners. Asymptomatic colonization in sexual active women is more prevalent compared to non-sexual women, postmenopausal women, and to sexual active men. During pregnancy the colonization rate of the genital tract by M. hominis varies in different studies from 5 to $75 \%$. Newborns are colonized during passage of the birth canal, thereafter the colonization rate decreases and $M$. hominis may be found only in small numbers of pre-pubertal girls [2,3]. M. hominis has been associated with both genitourinary tract and non-genital infections. However, so far it is assumed, that a M. hominis mono-infection may not be a primary cause of genitourinary infections, and that the evidence seems to be circumstantial at best [2]. However, M. hominis has been detected in the fallopian tubes and abscesses during pelvic inflammatory disease (PID) and in free abdominal fluid in several studies, but their presence is often associated with other pathogens, such as anaerobic bacteria, Ureaplasma species, Chlamydia trachomatis and Neisseria gonorrhoeae $[2,4]$. Other genitourinary infections, to which $M$. hominis may have been linked more or less, are non-gonococcal urethritis, urinary tract infections, bacterial vaginosis, chorioamnionitis, adverse pregnancy outcome, post-partum bacteraemia, and infection after invasive procedures. However, many of these infections are polymicrobial in origin, in which the role of commensal bacteria such as $M$. hominis is possibly underestimated [2,5-7]. The presence of these low-virulence microorganisms alone may not be sufficient to induce chorioamnionitis in pregnant women, but also the host immune response plays an important role in the outcome [4]. Therefore, more evidence is needed to show a causal relationship of $M$. hominis with these infections. Premature or low birth weight neonates may suffer from meningo-encephalitis, lung disease and subcutaneous abscesses often in association with chorioamnionitis. Male infertility is another topic in which the causal role of chronic infection with $M$. hominis has been questioned. In a recent meta-analysis an association between decreased sperm quality (morphology) and low sperm concentration and the presence of M. hominis DNA has been shown [7-9].

In contrast, clear cut extra-urogenital infections by $M$. hominis, such as arthritis, central nervous disease, endocarditis, prosthetic joint and bone infections, and soft tissue infections are reported and in some cases these infections may be fatal [1,10-12]. Probably, these infections arise as a consequence in the breach of genitourinary mucosa, followed by haematogenous spread to the different organs and tissues $[4,13]$. The main reasons these bacteria are able to cause disseminated infections, may be the immune status of the patient, the use of beta-lactams antibiotics in first line treatment of soft tissue infections, the lack of sensitive diagnostic assays, and often the low awareness of the potential invasiveness of $M$. hominis among clinicians. Therefore, the diagnosis is usually made only after several days or even weeks, or by coincidence if molecular assays or sequencing techniques are performed on normal sterile body sites $[1,11,12]$. However, these publications show the potential of $M$. hominis to cause invasive and disseminated infections. Immunosuppression, and hypogammaglobulinemia in particular, seems to be associated with disseminated extra-genitourinary $M$. hominis infections, and was seen in half of the patients [12,13]. In our patient hypogammaglobulinemia was induced by rituximab, a CD20 monoclonal antibody, which targets malignant CD20 expressing B cells in patients with non-Hodgkin lymphoma.

Diagnostic options for the diagnosis of $M$. hominis infections are limited. These bacteria do not possess a cell wall, and therefore they cannot be visualized in a Gram stain in clinical samples. Furthermore, $M$. hominis is a fastidious organism and a prolonged incubation of genitourinary cultures is necessary to produce visible growth, cultures are often overgrown by commensal flora, and specific Mycoplasma/ Ureaplasma culture is usually not performed in a routine laboratory. Molecular assays for these microorganisms are so far not widely spread in routine laboratories. Nevertheless, we believe that in the case of severe (extra) genitourinary infections, a broad screening for possible causative organisms in addition to $C$. trachomatis and $N$. gonorrhoeae is a reasonable policy. In our laboratory, an in house Taqman ${ }^{\star}$ Array Card is used for the simultaneous detection of 13 microorganisms, $C$. trachomatis, N. gonorrhoeae, Trichomonas vaginalis, M. hominis and M. genitalium, Ureaplasma urealyticum and U. parvum, Treponema pallidum, Herpes Simplex virus type 1 and 2, Cytomegalovirus, Adenovirus, and Haemophilus ducreyi. Only when significant high concentrations of $M$. hominis are found in genitourinary and deep seated samples, clinicians receive antibiotic advice on the lab report so they can decide whether the present symptoms can eventually be explained by M. hominis. In many commercial molecular assays for STI screening, the separate detection of $M$. hominis DNA is not included. On extra-genital samples often a broad-range bacterial PCR which uses a primer pair aimed at highly conserved DNA coding regions of bacterial rRNA is performed when culture stays negative [11].

${ }^{*}$ Corresponding author: Eric Nulens, Laboratory Medicine, Department of Medical Microbiology, AZ Sint -Jan Bruges - Ostend, Ruddershove 10, 8000, Bruges, Belgium, Tel: +32 504526 02; Fax: +32 504526 19; E-mail: eric.nulens@azsintjan.be

Received April 25, 2016; Accepted April 30, 2016; Published May 15, 2016

Citation: Nulens E, Reynders M (2016) Mycoplasma hominis: More than just An Innocent Bystander. J Antimicro 2: 114. doi: 10.4172/2472-1212.1000114

Copyright: $\odot 2016$ Nulens E, et al. This is an open-access article distributed under the terms of the Creative Commons Attribution License, which permits unrestricted use, distribution, and reproduction in any medium, provided the original author and source are credited. 


\begin{tabular}{|c|c|c|c|c|c|c|c|c|c|c|c|c|c|c|c|c|}
\hline & \multicolumn{2}{|c|}{$\begin{array}{c}\text { Bayraktar } \\
\text { [19] }\end{array}$} & \multicolumn{2}{|c|}{ Krausse [21] } & \multicolumn{2}{|c|}{ Messano [22] } & \multicolumn{2}{|c|}{ Diaz [23] } & \multicolumn{2}{|c|}{ Pónsai [20] } & \multicolumn{2}{|c|}{ Wang [17] } & \multicolumn{2}{|c|}{$\begin{array}{c}\text { Azizmohammadi } \\
{[24]}\end{array}$} & \multicolumn{2}{|c|}{ Pignanelli [18] } \\
\hline & MH & UU & MH & UU & MH & UU & MH & UU & MH & UU & MH & UU & MH & UU & MH & UU \\
\hline \multirow[t]{3}{*}{ Number of Isolates } & 5 & 27 & 290 & 179 & 128 & 0 & 50 & 154 & 41 & 373 & 0 & & 10 & 32 & 99 & 0 \\
\hline & \multicolumn{2}{|c|}{$\mathrm{I}+\mathrm{R}$} & \multicolumn{2}{|c|}{$\mathrm{R}$} & \multicolumn{2}{|c|}{$\mathrm{R}$} & \multicolumn{2}{|c|}{$\mathrm{I}+\mathrm{R}$} & \multicolumn{2}{|c|}{$\mathrm{R}$} & \multicolumn{2}{|c|}{$\mathrm{R}$} & \multicolumn{2}{|c|}{$\mathrm{R}$} & \multicolumn{2}{|c|}{ I+R } \\
\hline & \multicolumn{2}{|c|}{$(\%)$} & \multicolumn{2}{|c|}{$(\%)$} & \multicolumn{2}{|c|}{$(\%)$} & \multicolumn{2}{|c|}{$(\%)$} & \multicolumn{2}{|c|}{$(\%)$} & \multicolumn{2}{|c|}{$(\%)$} & \multicolumn{2}{|c|}{$(\%)$} & \multicolumn{2}{|c|}{$(\%)$} \\
\hline Tetracycline & 0 & 0 & 11.4 & 2.8 & 12 & - & 52 & 33.8 & 12.2 & 4.0 & 0 & 4.8 & 40 & 50 & 10.1 & - \\
\hline Doxycycline & 0 & 0 & 10.0 & 1.1 & - & - & 36 & 24 & 2.4 & 2.4 & 0 & 2.0 & 20 & 21.9 & 4.0 & - \\
\hline Minocyclin & - & - & 13.1 & 2.8 & - & - & 20 & 25.3 & - & - & 0 & 5.4 & - & - & - & - \\
\hline Pefoxacin & - & - & - & - & - & - & 24 & 25.3 & - & - & - & - & 20 & 34.8 & - & - \\
\hline Ofloxacin & 80 & 88.9 & 1.7 & 1.7 & 50 & - & 70 & 72.8 & 4.9 & 25.2 & 84.4 & 77.9 & 60 & 62.5 & 74.8 & - \\
\hline Ciprofloxacin & 40 & 92.6 & 7.9 & 16.2 & - & - & - & - & - & - & 82.2 & 95.2 & 70 & 78.1 & 75.8 & - \\
\hline Clindamycin & - & - & 0 & 42.5 & 50 & - & 28 & 26.0 & 4.9 & 75.1 & - & - & 30 & 31.2 & & - \\
\hline Josamycin & 20 & 7.4 & 3.4 & 1.7 & 0 & - & - & - & - & - & 8.9 & 12.1 & NA & 15.6 & 9.1 & - \\
\hline Azithromycin & 60 & 44.4 & 98.6 & 7.3 & 88 & - & 92 & 34.4 & - & 9.6 & 97.8 & 30.8 & 30 & 40.6 & 98.0 & - \\
\hline Clarithromycin & 40 & 11.1 & 99.0 & 4.5 & 75 & - & 88 & 70.8 & - & - & 95.6 & 1.6 & 20 & 28.1 & 88.9 & - \\
\hline Roxithromycin & NA & NA & 98.3 & 5.6 & - & - & NA & NA & - & - & 95.6 & 4.5 & - & - & & - \\
\hline Erythromycin & 100 & 40.7 & 95.9 & 20.7 & 88 & - & 96 & 50.0 & - & 81.2 & 100 & 21.9 & 40 & 56.2 & 89.9 & - \\
\hline Pristinamycin & 0 & 0 & - & - & 0 & - & - & - & - & - & - & - & - & 12.5 & 4.0 & - \\
\hline
\end{tabular}

MH: Mycoplasma hominis; UU: Ureaplasma urealyticum; -: Not available

Table 1: Summary of resistance of $M$. hominis and $U$. urealyticum in different studies

Susceptibility testing of Mycoplasma isolates in a routine bacteriology laboratory is also challenging, and for genitourinary infection is usually not performed. Despite numerous publications, there have been no universally accepted or standardized broth dilutionor agar-based methods designating the optimum testing conditions, $\mathrm{pH}$, media, and duration of incubation. The lack of a consensus method for disk susceptibility testing or MIC determination with antibiotic gradient strips or micro dilution has resulted in considerable confusion regarding the antimicrobial activities of various drugs against these organisms [14]. Understandably, at this moment there are no CLSI or EUCAST breakpoints available. Currently, commercial kits for the combined identification and susceptibility testing in liquid media are used in routine laboratory, in which the presence of $M$. hominis in genitourinary samples is detected by biochemical tests, simultaneously with susceptibility testing $[15,16]$. These kits are easy to use, the results are available after one day of incubation, and are often applied in studies to determine activities of antibiotics. In Table 1 the summary of susceptibility testing of $M$. hominis and $U$. urealyticum isolates from genitourinary samples in recent studies is shown [17-24]. These results shown a diversity in resistance rates of these isolates against different antibiotic classes. The isolates are from mostly pregnant women, asymptomatic patients, and patients with genitourinary complaints. The activity of some antibiotics is further compromised if the cumulative resistance of $M$. hominis and $U$. urealyticum, against the antibiotics was reported $[16,17,25]$. Doxycycline remains one of the most active antibiotics; however, in some studies resistance up to $36 \%$ was reported. Resistance against tetracyclines was significantly different (1.8-95\%), dependent of the country and continent [18]. A reason may be that M. hominis is transferred through sexual intercourse, and this might promote the spread of resistant clones [18]. On the other hand, moxifloxacin is very active against $M$. hominis and other genital Mycoplasma and Ureaplasma species, and very low $\mathrm{MIC}_{90}$ values were reported [26]. M. hominis resistance against moxifloxacin so far is rare, but has recently been reported [12]. M. hominis is resistant to 14- and 15-membered macrolides, including erythromycin, azithromycin, and clarithromycin, due to a mutation in domain $\mathrm{V}$ of $23 \mathrm{~S}$ rRNA, mutations in ribosomal protein L4 gene and antibiotic efflux as well [27]. Macrolides are not active against $M$. hominis in contrast to $M$. genitalium, and other Mycoplasma species, except for josamycin, a newer macrolide formulation; however, this antibiotic may not be available in some countries like Belgium. Clindamycin is the most active agent against $M$. hominis [28,29]. Furthermore, tigecycline, has shown to be very active $\left(\mathrm{MIC}_{50} / \mathrm{MIC}_{90}, 0.25 / 0.5 \mathrm{mg} / \mathrm{ml}\right.$; range, 0.125 $\mathrm{mg} / \mathrm{ml}-0.5 \mathrm{mg} / \mathrm{ml}$ ), while linezolid shows only a modest activity against M. hominis $\left(\mathrm{MIC}_{90} 8 \mathrm{mg} / \mathrm{ml}\right.$, range $2-8 \mathrm{mg} / \mathrm{ml}$ ) [1]. Beta-lactam and glycopeptide antibiotics are not effective in the treatment of $M$. hominis, due to the lack of a bacterial cell wall and thus peptidoglycan, the main action site of beta-lactams and glycopeptides. Therefore, antibiotics from other classes are the first choice.

The treatment of patients with severe genitourinary infections is different from the treatment of patient with extra-genitourinary tract infections. In the first, a common empiric antibiotic is used against the most probable pathogenic species, namely C. trachomatis, N. gonorrhoeae, M. genitalium, Enterobacteriaceae, and anaerobic bacteria. Centers for Disease Control and Prevention recommend a regimen containing doxycycline [2]. However, tetracyclines and quinolones are no options in pregnant women, therefore josamycin or clindamycin would be reasonable alternatives; the role of linezolid needs to be further examined [18]. In extra-urogenital infections by $M$. hominis, doxycycline is also recommended, sometimes in association with surgery, dependent of the infection site $[2,11]$. With our patient, the clinical response to moxifloxacin was only partial, and the patient recovered quickly after clindamycin therapy was started, but he was further treated as an outpatient for several weeks. The duration of the treatment is, due to individual case reports only, dependent on clinical judgement, and should continue until clinical signs of infection have completely resolved [2]. Microbiologists and infectious disease specialist should be aware, that these low virulence micro-organisms, may be resistant to the common used antimicrobials $[12,18]$. Therefore, in case of infections caused by non-cultivable micro-organisms, such as M. hominis, it is advised that some kind of susceptibility assay is performed, as a result of significant geographical and age related differences in the susceptibility between isolates [10,18]. Some molecular assays for the detection of mutation resistance markers at molecular level, which might be responsible for therapy failure, such 
Citation: Nulens E, Reynders M (2016) Mycoplasma hominis: More than just An Innocent Bystander. J Antimicro 2: 114. doi: 10.4172/24721212.1000114

as with tetracycline, and quinolones resistance already exist, however these techniques are mostly used for research purposes [10].

In conclusion, in many studies the role of M. hominis in genitourinary infections so far has not been clear. Nevertheless, there are some reports, suggestive of a causal pathophysiologic impact of this bacterium in the lower and upper genital tract. Additionally $M$. hominis infection is probably an important cause of male infertility, and publications of severe invasive infections by $M$. hominis show that this bacterium should not just be underestimated as an innocent by stander.

\section{References}

1. Nulens E, Van Praet J, Selleslag D, Van Landschoot T, Dekeyzer D, et al. (2015) A disseminated Mycoplasma hominis infection in a patient with an underlying defect in humoral immunity. Infection.

2. Baum SG (2016) Mycoplasma hominis and Ureaplasma urealyticum infections.

3. Capocciaa R, Greubb G, Baud D (2013) Ureaplasma urealyticum, Mycoplasma hominis and adverse pregnancy outcomes. Curr Opin Infect Dis 26: 231-240.

4. Czikk MJ, McCarthy FP, Murphy KE (2011) Chorioamnionitis: from pathogenesis to treatment. Clin Microbiol Infect 17: 1304-1311.

5. Bachmann LH, Manhart LE, Martin DH, Seña AC, Dimitrakoff J, et al. (2015) Advances in the Understanding and Treatment of Male Urethritis. Clin Infect Dis 8: 763-769.

6. Onderdonk AB, Delaney ML, Fichorova RN (2016) The Human Microbiome during Bacterial Vaginosis. Clin Microbiol Rev 29: 223-238.

7. Vouga M, Greub G, Prod'hom G, Durussel C, Roth-Kleiner M, et al. (2014) Treatment of genital mycoplasma in colonized pregnant women in late pregnancy is associated with a lower rate of premature labour and neonatal complications. Clin Microbiol Infect 20: 1074-1079.

8. Gdoura R, Kchaou W, Chaari C, Znazen A, Keskes L, et al. (2007) Ureaplasma urealyticum, Ureaplasma parvum, Mycoplasma hominis and Mycoplasma genitalium infections and semen quality of infertile men. BMC Infect Dis 7: 129.

9. Huang C, Zhu HL, Xu KR, Wang SY, Fan LQ, et al. (2015) Mycoplasma and ureaplasma infection and male infertility: a systematic review and metaanalysis. Andrology 3: 809-816.

10. MacKenzie CR, Nischik N, Kram R, Krauspe R, Jäger M, et al. (2010) Fatal outcome of a disseminated dual infection with drug-resistant Mycoplasma hominis and Ureaplasma parvum originating from a septic arthritis in an immunocompromised patient. Int J Infect Dis 3: 307-309.

11. Gagneux-Brunon A, Grattard F, Morel J, Suy F, Fuzellier JF, et al. (2015) Mycoplasma hominis, a rare but true cause of infective endocarditis. J Clin Microbiol 53: 3068-3071.

12. Fernández S, Nicolás D, Pericás JM, Castro Rebollo P, Vila J, et al. (2014)A case of Mycoplasma hominis disseminated infection in a human immunodeficiency virus-1-infected pregnant woman with hypogammaglobulinemia. J Microbiol Immunol Infect 1684-1182.

13. Meyer RD, Clough W (1993) Extragenital Mycoplasma hominis Infections in Adults: Emphasis on Immunosuppression. Clin Infect Dis 17: 243-249.

14. Waites KB, Duffy LB, Bébéar CM, Matlow A, Talkington DF, et al. (2012) Standardized methods and quality control limits for agar and broth microdilution susceptibility testing of Mycoplasma pneumoniae, Mycoplasma hominis, and Ureaplasma urealyticum. J Clin Microbiol 50: 3542-3547.

15. Quentin R, Verdon R (2012) Pelvic inflammatory disease : Microbiological bases of diagnosis and treatment. J Gynecol Obstet Biol Reprod (Paris) 41: 850-863.

16. Redelinghuys MJ, Ehlers MM, Dreyer AW, Lombaard HA, Kock MM (2014) Antimicrobial susceptibility patterns of Ureaplasma species and Mycoplasma hominis in pregnant women. BMC Infect Dis 14: 171.
17. Wang QY, Li RH, Zheng LQ, Shang XH (2014) Prevalence and antimicrobia susceptibility of Ureaplasma urealyticum and Mycoplasma hominis in female outpatients, 2009-2013. J Microbiol Immunol Infec 1684-1182.

18. Pignanelli S, Pulcrano G, Schiavone P, lula VD, Catania MR (2015) In vitro antimicrobial susceptibility of Mycoplasma hominis genital isolates. Indian J Dermatol Venereol Leprol 81: 286-288.

19. Bayraktar MR, Ozerol IH, Gucluer N, Celik O (2010) Prevalence and antibiotic susceptibility of Mycoplasma hominis and Ureaplasma urealyticum in pregnant women. Int J Infect Dis 14: 90-95.

20. Pónyai K, Mihalik N, Ostorházi E, Farkas B, Párducz L, et al. (2013) Incidence and antibiotic susceptibility of genital mycoplasmas in sexually active individuals in Hungary. Eur J Clin Microbiol Infect Dis 32: 1423-1426.

21. Krausse R, Schubert S (2010) In-vitro activities of tetracyclines, macrolides, fluoroquinolones and clindamycin against Mycoplasma hominis and Ureaplasma ssp. isolated in Germany over 20 years. Clin Microbiol Infect 16 1649-1655.

22. Messano GA, Petti S (2011) The antibiotic resistance a public health problem : the case of genital mycoplasmosis. Ig Sanità Pubbl 67: 697-706.

23. Díaz L, Cabrera LE, Fernández T, Ibáñez I, Torres Y, et al. (2013) Frequency and antimicrobial sensitivity of Ureaplasma urealyticum and Mycoplasma hominis in patients with vaginal discharge. MEDICC Rev 15: 45-47.

24. Azizmohammadi S, Azizmohammadi S (2015) Antimicrobial Susceptibility Patterns of Ureaplasma urealyticum and Mycoplasma hominis Isolated From Pregnant Women. Iran Red Crescent Med J 17: 17211.

25. De Francesco MA, Caracciolo S, Bonfanti C, Manca N (2013) Incidence and antibiotic susceptibility of Mycoplasma hominis and Ureaplasma urealyticum isolated in Brescia, Italy, over 7 years. J Infect Chemother 19: 621-627.

26. Bébéar CM, de Barbeyrac B, Pereyre S, Renaudin H, Clerc M, et al. (2008) Activity of moxifloxacin against the urogenital mycoplasmas Ureaplasma spp., Mycoplasma hominis and Mycoplasma genitalium and Chlamydia trachomatis. Clin Microbiol Infect 14: 801-805

27. Vargović M, Pasini M, Papić N, Andrašević S, Markotić A, et al. (2014) Antimicrobial susceptibility of Ureaplasma urealyticum and Mycoplasma hominis. Sex Transm Infect 90: 69.

28. Waites KB, Crabb DM, Duffy LB (2008) Comparative in vitro activities of the investigational fluoroquinolone DC-159a and other antimicrobial agents against human Mycoplasmas and Ureaplasmas. Antimicrob Agents Chemother 52: 3776-3778.

29. Waites KB, Crabb DM, Duffy LB (2009) Comparative in vitro susceptibilities of human Mycoplasmas and Ureaplasmas to a new investigational ketolide, CEM101. Antimicrob Agents Chemother 53: 2139-2141. 